\title{
Dicionários onomasiológicos para intérpretes novatos: o caso do Longman Language Activator
}

Patrizia Cavallo*

\section{Introdução}

A literatura sobre os recursos lexicográficos empregados pelos intérpretes ${ }^{1}$, profissionais que trabalham com a tradução oral, em especial nas modalidades simultânea e consecutiva por ocasião de eventos bi- ou multilíngues tais como congressos, palestras, encontros políticos e de negócios, entre outros, é significativamente limitada. Na pesquisa nacional e internacional, o estudo da lexicografia está relacionado quase que de forma exclusiva à área da tradução escrita, ao passo que as necessidades dos intérpretes são abordadas geralmente sob a perspectiva terminológica, devido às dificuldades que o léxico especializado das muitas áreas profissionais acarreta para esse profissional ${ }^{2}$. De forma muito simplificada, considerando-se a lexicografia como a ciência que estuda a elaboração de dicionários relativos ao léxico geral de uma língua (ao passo que a terminologia foca no léxico especializado), resulta fundamental refletir sobre a importância de recursos lexicográficos para intérpretes novatos na fase de preparação para um evento de interpretação, ressaltando o papel

\footnotetext{
* Patrizia Cavallo é doutoranda em Lexicografia, Terminologia e Tradução: Relações Textuais (UFRGS), mestre em Interpretação (UNIBO, Itália) e em Literatura Comparada (UFRGS), tradutora e intérprete de conferências.

${ }^{1}$ Qualquer referência à interpretação, neste trabalho, diz respeito à interpretação entre línguas orais e não envolvendo línguas de sinais.

${ }^{2}$ Mesmo os estudos que abordam essa temática são ainda muito escassos no Brasil (entre esses, Nejm, 2011; Cavallo, 2017).
} 
especial que dicionários onomasiológicos como o LLA (Longman Language Activator, 1993[1997]) podem desempenhar na tarefa de tais profissionais.

O recorte específico deste trabalho diz respeito aos intérpretes novatos $^{3}$ e à importância que um dicionário onomasiológico como o LLA representa para a sua preparação linguística. É evidente que se trata de uma temática pouco investigada em razão de que a) competências linguísticas sólidas em, pelo menos, duas línguas de trabalho são dadas por óbvias quando os intérpretes ingressam no mercado de trabalho; b) a preparação terminológica preocupa muito mais os intérpretes ${ }^{4}$ e c) obras lexicográficas específicas e adequadas para este perfil de profissional são raras. Porém, esse usuário especial de dicionários não pode ser negligenciado, sendo fundamental refletir sobre os recursos que poderia vir a utilizar e sobre as competências linguísticas de intérpretes novatos.

A partir dessas justificativas, este trabalho é qualitativo-descritivo: a revisão de literatura sobre lexicografia para intérpretes, a discussão sobre a preparação antes de um evento de interpretação e as combinações linguísticas de intérpretes novatos serão seguidas pela análise geral da micro- e macroestrutura do LLA, dicionário onomasiológico de língua inglesa, acompanhada de uma reflexão sobre a sua utilidade para intérpretes novatos que trabalham com essa língua.

\section{Panorama dos estudos sobre as necessidades lexicográficas dos intérpretes}

Vários estudos foram publicados avaliando e descrevendo as necessidades terminológicas dos intérpretes, como, por exemplo, os realizados por Gile (1985; 1987) e por Moser-Mercer (1992). Mais recentemente, o tema foi

\footnotetext{
${ }^{3}$ Resulta difícil encontrar uma definição unânime de "intérprete novato" na literatura. Alguns autores afirmam que os novatos são os que têm "little or no experience in a particular domain" (Moser-Mercer et al., 2000, p. 108), ao passo que outros os definem como estudantes de interpretação cursando o segundo (último) ano de estudos (Köpke; Nespoulous, 2006). Também existem entendimentos que consideram "novatos" os profissionais com menos de 150 dias de trabalho (Servoz-Gavin, 2014, p. 44), o que poderia corresponder a vários anos de profissão, dependendo das ocasiões de trabalho. Para fins deste trabalho, a definição usada se encaixa entre a primeira e a segunda possibilidade, isto é, intérpretes que recém terminaram um percurso de formação em interpretação e/ou já trabalharam em alguns eventos.

${ }^{4}$ Pesquisa de campo ainda não realizada, mas, pelas publicações muito mais numerosas sobre esse assunto, e pela convivência com outros intérpretes, se deduz que seja esse o caso.
} 
retomado graças aos trabalhos de Bilgen (2009), de Rodríguez e Schnell (2009), de Bertaccini e Veronesi (2010) e de Nejm (2011), além do atualíssimo estudo realizado por Corpas Pastor, Costa e Durán Muñoz (2014) sobre as ferramentas usadas pelos intérpretes para gestão da terminologia. Porém, a mesma quantidade de pesquisas não se faz presente no que diz respeito às necessidades lexicográficas dos intérpretes, uma vez que a grande maioria dos trabalhos foca mais na relação entre a lexicografia mono/bilíngue e a atividade de tradução escrita (Sin-Wai, 2004; San Vicente, 2006; Sánchez, Porciel e Serrat, 2014; somente para citar alguns).

Entre as poucas contribuições que relacionam a área da lexicografia com as atividades de interpretação, é interessante citar, em ordem cronológica para fins de um melhor entendimento sobre o panorama atualmente disponível sobre tal assunto, os seguintes trabalhos: Peter Mead, "Interpreting: the Lexicographers' View" (1999), apesar de ele tratar apenas das definições de "interpretação" e "intérprete" encontradas em dicionários e outras obras lexicográficas; Cristina Valentini, "Uso del Computer in Cabina di Interpretazione" (2002), que constitui um levantamento sobre as necessidades terminológicas dos intérpretes antes e durante a interpretação, mas cita também as preferências de dicionários manifestadas por eles; Andrejs Veisbergs, "Dictionaries and Interpreters" (2006), um dos poucos estudos que realmente comenta o uso dos dicionários por parte dos intérpretes; Franziska Heimburger, "Getting at language use in translation history through dictionaries produced for interpreters" (2010), trabalho que trata do uso do dicionário de Plumon pelos intérpretes (e oficiais) militares durante a Primeira Guerra Mundial, e Sarah Tripepi Winteringham, "The usefulness of ICTs in interpreting practice" (2010), que tem o seu enfoque nas tecnologias a serviço dos intérpretes, destacando a importância dos dicionários eletrônicos na prática desses profissionais.

Esse escasso panorama demonstra que falta, na área dos Estudos da Interpretação, uma análise aprofundada dos recursos, principalmente dicionários, usados pelos intérpretes antes, durante e após o trabalho de interpretação. Como afirma Kalina (2002, p. 126), a qualidade da tarefa de interpretação é o resultado direto de fatores que podem ser reunidos em 
quatro grupos, isto é, pre-process prerequisites (habilidades e competências, definição da tarefa, preparação, definição do encargo), peri-process conditions (número de participantes, línguas de trabalho, equipamento técnico, equipe, duração do evento, disponibilização dos documentos, etc.), inprocess requirements (conhecimentos e pressuposições, requisitos relativos à língua de chegada, entre outros) e post-process efforts (follow-up terminológico, documentação, controle de qualidade, etc.). As quatro fases são importantes para determinar o sucesso do trabalho dos profissionais envolvidos, mas neste estudo enfocaremos especificadamente os prérequisitos antes do processo, ou seja, a fase de preparação do intérprete (novato) e o uso de dicionários.

\section{A preparação do intérprete e o uso de recursos lexicográficos}

Conforme anunciado antes, o objetivo deste trabalho não é discutir quais recursos lexicográficos são usados e/ou seriam mais apropriados durante a atividade de interpretação, mas antes da tarefa, pois, como enfatizado por vários pesquisadores (Nejm, 2011; Servoz-Gavin, 2014; Bajo, Díaz-Galaz, Padilla, 2015, entre outros), é sobretudo a fase de preparação que faz diferença na qualidade do serviço de interpretação oferecido. É evidente que, durante o seu labor, o intérprete está submetido a uma grande carga cognitiva, sendo essa uma das razões pelas quais esse profissional não pode deixar para estudar e esclarecer dúvidas durante o evento (excetuando alguns casos pontuais). Existem ainda razões de ordem prática, determinadas pelo tipo de situação comunicativa e pelo setting sobre um palco e/ou no meio do(s) palestrante(s) no caso da interpretação consecutiva, ou dentro de uma cabine no caso da interpretação simultânea - pelas quais se infere que o intérprete não consegue fazer pesquisa, buscar equivalentes e/ou solucionar todas as suas dúvidas linguísticas de forma satisfatória durante o evento. No caso específico da interpretação simultânea, em que o intérprete geralmente se encontra em uma cabine, e dependendo da rapidez da fala do palestrante, da dificuldade do assunto, da disponibilidade de seu colega etc., é possível que ele consiga consultar alguma versão eletrônica de dicionários, glossários, enciclopédias ou outro material, mas isso não significa que sua preparação possa depender de tal 
fato. Esta impossibilidade (de que o intérprete pesquise e estude apenas durante o evento) é também comprovada pelos estudos conduzidos por Gile (1985; 1999; 2009), responsável pela elaboração de um modelo de esforços e de equilíbrio em interpretação simultânea e consecutiva e pela Tightrope Hypothesis, segundo a qual os intérpretes trabalhariam, na maioria do tempo, perto de seu nível de saturação. Tal condição faz com que qualquer aumento dos requisitos de capacidade de processamento ou má gestão dos recursos cognitivos possa levar a uma sobrecarga ou déficit de atenção, com consequente deterioração da qualidade e presença de falhas, omissões etc.

Pelas razões acima consideradas, de ordem cognitiva e prática, é possível afirmar que os intérpretes devem estudar e se preparar otimamente antes da execução do trabalho. Sua preparação caracteriza-se, portanto, por uma perspectiva de previsão e antecipação, contrariamente à preparação dos tradutores que é, na maioria dos casos, posterior (ou seja, após ter recebido o material a traduzir) (Cavallo, 2017). A fase da preparação é ainda mais importante no caso de intérpretes novatos, os quais são o foco deste trabalho, pois, conforme afirma Servoz-Gavin (2014), autora de uma dissertação de mestrado sobre estratégias de preparação e diferenças entre intérpretes iniciantes e experientes:

\begin{abstract}
Les informations obtenues au cours de l'étude montrent que les novices apportent un soin particulier au travail de préparation. Ils entament leur préparation plus tôt que les experts, et y consacrent plus de temps. Ce comportement ne constitue pas une surprise en soi de la part de personnes débutant dans la carrière. En effet, méconnaissant encore le fonctionnement des conférences et n'ayant pas le bagage cognitif accumulé par les experts sur de nombreux sujets, les novices sont obligés de mener une préparation plus poussée en termes de recherche de l'information et d'acquisition des connaissances que les experts. Ainsi, le temps passé à se préparer chez les novices est le symptôme d'une compétence qu'ils n'ont que partiellement acquise et qui consiste à cibler sa préparation sur ce qui est important et pertinent pour l'interprétation (Servoz-Gavin, 2014, p. 98, grifo nosso).
\end{abstract}

Conforme é possível observar nesse trecho, os intérpretes novatos dedicariam mais tempo para a fase de preparação, focando na "busca de 
informações" e na "aquisição de conhecimentos sobre vários assuntos". Além disso, acreditamos que os intérpretes novatos também realizam uma preparação linguística, em especial no caso de uma interpretação para a língua estrangeira ${ }^{5}$. Segundo Rodríguez e Schnell (2009), esses profissionais deveriam realizar, antes de qualquer evento de interpretação, uma preparação de quatro tipos: temática, linguística, tradutória e de interpretação. Durante a primeira, eles se tornam familiarizados com o assunto do evento através da leitura de vários documentos (enviados ou não pelos organizadores e/ou palestrantes) para, sucessivamente, realizar a extração terminológica e a criação de glossários. As fases de preparação tradutória e de interpretação representam dois momentos em que o intérprete encontraria os equivalentes na outra língua, destacando os verbos mais significativos, palavras-chave e outras informações importantes a serem inseridas em seus glossários finais, além de realizar exercícios de interpretação ${ }^{6}$ focando na modalidade específica (consecutiva ou simultânea) que será utilizada no evento, treinando suas técnicas de interpretação e memória, entre outras. Na fase de preparação linguística, de especial interesse para este estudo, o intérprete analisa o material compilado, focando sua atenção na busca de sinônimos, hiperônimos e acrônimos, entre outros (Rodríguez; Schnell, 2009). No caso de intérpretes novatos em preparação para a atividade de "produção" em língua estrangeira, é previsível que eles também realizem as seguintes ações: revisão de padrões colocacionais, resolução de eventuais dúvidas gramaticais e fonéticas, entre outras, além da busca de fraseologias e de itens lexicais não conhecidos ${ }^{7}$. É nessa fase que os dicionários são de fundamental importância, inclusive os onomasiológicos, conforme será explicado abaixo no item 5 .

\footnotetext{
${ }^{5}$ Para fins deste estudo, considera-se um intérprete cuja língua materna não é o inglês e que deve interpretar para a sua língua B, isto é, neste caso específico, o inglês. O foco do trabalho é a produção em língua estrangeira, que também é o principal objetivo de um dicionário onomasiológico como o Longman Language Activator.

${ }^{6}$ Supomos, por experiência, que isso aconteça no caso de intérpretes novatos, mas ainda não foram conduzidos estudos confirmando tal hipótese.

${ }^{7}$ Um estudo de campo envolvendo intérpretes novatos seria muito importante para poder confirmar e analisar o tipo de preparação linguística empreendida e os recursos lexicográficos utilizados nessa etapa.
} 
Entre os tradicionais recursos lexicográficos utilizados pelos intérpretes nessa etapa preparatória, conforme apontam Valentini (2002) e Veisbergs (2006), estão os dicionários mono- e bilíngues, as enciclopédias, os dicionários de pronúncia, os de sinônimos e antônimos. Além disso, obviamente, é muito importante para a preparação a documentação especializada, livros e outras referências específicas sobre o assunto a ser tratado e, sobretudo, todos os documentos e materiais disponibilizados pelos organizadores e/ou palestrantes do evento. Veisbergs (2006) considera que os intérpretes "constitute a particular and slightly odd category of dictionary users because of their peculiar needs and conditions of use of lexicographical sources" (Veisbergs, 2006, p. 1219). Segundo o estudioso, isso ocorre tanto por causa da elevada proficiência linguística dos intérpretes (aliada à consequente necessidade de dicionários altamente sofisticados e atualizados) quanto por causa das características intrínsecas das modalidades de interpretação e da falta de tempo para procurar uma palavra em um dicionário, por exemplo, durante a atividade de interpretação.

\section{As combinações linguísticas do intérprete novato}

É essencial refletir brevemente sobre as combinações linguísticas de um intérprete ao terminar um curso de formação em interpretação e/ou ao ingressar no mercado de trabalho. Com exceção de alguns casos, o intérprete traduz geralmente tanto para a sua língua materna quanto para a(s) sua(s) língua(s) B. A AIIC (Associação Internacional de Intérpretes de Conferências) informa em seu site que a língua $B$ seria aquela em que um intérprete é perfeitamente fluente, mas não é a sua língua materna (língua A) ${ }^{8}$. Por outro lado, a língua (ou as línguas) C seria aquela com a qual o intérprete trabalha de forma passiva, isto é, traduzindo somente a partir dela. A língua $B$, por contraste, é uma língua ativa, por meio da qual o intérprete trabalha nas duas direções (de A para B e de B para A). Também a APIC (Associação Profissional de Intérpretes de Conferências) afirma que a língua B seria a "língua adquirida na qual o intérprete trabalha a partir de

8 De acordo com o site https://aiic.net/page/4004/what-are-working-languages-to-a-conferenceinterpreter/lang/1 
uma ou mais de suas outras línguas, materna ou adquirida. $\mathrm{O}$ intérprete tem pleno comando da língua $B$, tanto no que se refere à compreensão quanto à expressão oral" ${ }^{\prime \prime}$.

No mercado, é muito comum que o intérprete traduza de e para as suas línguas A e B. Tal fato é ressaltado também pela pesquisadora Patrícia Camargo, a qual afirma que "apesar de não haver estudos conclusivos no par de línguas português-inglês, podemos afirmar que o mesmo acontece no Brasil, ou seja, os intérpretes são solicitados a interpretar para a língua B com frequência" (Camargo, 2014, p. 24). Outra confirmação é dada pela estrutura da maioria dos cursos de formação de intérpretes na Europa e na América do $\mathrm{Sul}^{10}$, os quais oferecem disciplinas de interpretação de e para a(s) língua(s) estrangeira(s) de estudo.

Consequentemente, é possível deduzir, pela experiência de mercado da autora do presente trabalho e pelas disciplinas oferecidas em cursos de formação de intérpretes no Brasil e no exterior, que os intérpretes novatos também traduzem para a língua $B$. Isso se deve também às características intrínsecas de um evento de interpretação, no qual, na maioria das vezes, é preciso traduzir tanto para o público quanto para o palestrante, como na fase de perguntas e respostas ao final de uma palestra. Por tal motivo, os intérpretes devem realizar a sua preparação não somente para fins de compreensão da língua B, mas também para a sua produção. Contudo, embora suas competências linguísticas ao final de um curso de interpretação correspondam a um domínio de alto nível da língua $\mathrm{B}$, não significa que eles não precisem consultar dicionários para variados fins, uma vez que também na própria língua materna às vezes é necessário (e aconselhável) fazê-lo. É evidente, assim, a necessidade de os intérpretes terem à disposição recursos lexicográficos monolíngues de alto nível para resolver, ao longo da fase de preparação, dúvidas de ordem semântica e sintática, verificar a pronúncia, buscar sinônimos e fraseologias, entre outros.

\footnotetext{
${ }^{9}$ De acordo com o site http://www.apic.org.br/classificacao-linguistica/

10 O levantamento sobre os currículos de cursos de formação em interpretação nessas regiões geográficas está sendo atualmente conduzido no âmbito da pesquisa de Doutorado da autora do presente trabalho.
} 


\section{Dicionários onomasiológicos para intérpretes novatos: o caso do LLA}

O levantamento conduzido entre 2000 e 2001 por Cristina Valentini, da Universidade de Bolonha, com base em questionários dirigidos a membros das principais associações de intérpretes da Itália e também aos sócios da AIIC (Associação Internacional de Intérpretes de Conferência), além de outros intérpretes freelance do Serviço de Interpretação da União Europeia, demonstrou que os intérpretes manifestam preferência pelo uso de dicionários bilíngues em relação aos monolíngues (devido à busca dos equivalentes), e usam mais recursos online do que os disponíveis em CDROM. Na seção outros, os intérpretes apontam a internet e dicionários etimológicos como demais recursos utilizados.

Também Nejm, para fins de seu estudo de 2011 (p. 86-91), enviou questionários para intérpretes que atuam no mercado brasileiro e, pela resposta fornecida por vinte e três deles, constatou-se que mais da metade utiliza dicionários na fase da preparação e de elaboração de glossários, sendo que 17,4\% incluem informações sobre pronúncia, além de acrônimos e explicações dos termos. Porém, considerando que somente $13 \%$ dessa amostra poderiam ser considerados intérpretes 'novatos', pois declaram ter de 1 a 5 anos de experiência, fica evidenciado o motivo de as respostas focarem mais nas necessidades terminológicas do que naquelas estritamente relacionadas ao léxico geral.

Tratando-se de levantamentos sobre a preparação terminológica dos intérpretes, e quase não havendo novatos entre os entrevistados, o uso de dicionários de tipo onomasiológico não aparece em decorrência de duas razões: em primeiro lugar, eles não são muito conhecidos pela comunidade de tradutores/intérpretes e pelo público em geral e, em segundo, assim como a maioria deles está configurada atualmente, sua consulta nem sempre é fácil e rápida, pois estão ordenados com base em uma ontologia, isto é uma hierarquia semântica baseada em uma classificação específica dos fenômenos do mundo, presente no início ou no final do dicionário, a partir da qual o usuário deve procurar a "ideia" que lhe interessa. O emprego do termo onomasiologia, segundo Babini (2006), remonta a 1903, com um estudo sobre os nomes das partes do corpo humano nas línguas 
românicas conduzido por Zauner, e vê seu desenvolvimento sobretudo no âmbito das línguas românicas, por meio de investigações científicas realizadas na Europa. Termos como "ideológico" e "analógico" são usados como sinônimos de dicionário "onomasiológico", os quais, apesar de apresentarem objetos e estruturas ligeiramente diferentes, têm o mesmo ponto de partida, ou seja, o significado. De fato, como afirma Bugueño Miranda (2014, p. 226), dicionários baseados na perspectiva semasiológica possuem uma "disposição do léxico visando ao significado", enquanto que, nos onomasiológicos, há "uma ordenação macroestrutural que parte do significado [...] para obter os seus significantes ou designações". Segundo o estudioso, a perspectiva semasiológica ou onomasiológica de um dicionário é apenas uma distinção dentro dos critérios linguísticos segundo os quais pode ser classificada uma obra lexicográfica (Bugueño Miranda, 2014, p. 225).

Apesar de o princípio onomasiológico adotado por poucos dicionários e algumas ferramentas para intérpretes não ser visto muito favoravelmente pela maioria dos profissionais, pois tornaria esse processo, já muito sobrecarregado do ponto de vista cognitivo, ainda mais lento devido às peculiaridades das estruturas onomasiológicas (Rodriguez; Schnell, 2009), é nossa convicção que esses recursos são, mesmo assim, importantes na fase de preparação linguística por parte de intérpretes novatos. Em especial porque, no caso específico do dicionário em análise no presente trabalho, a estrutura é de fácil acesso, eis que ele contém, ao final, um índice de todos os lemas contidos no dicionário, acompanhados do número dos respectivos parágrafos.

O dicionário LLA (1993 [1997]), lançado em 1993 pelo Longman Group, é um recurso lexicográfico monolíngue de inglês muito inovador, "aimed at helping intermediate to advanced students produce language, in other words, to encode their ideas" (LLA, 1993 [1997], Introduction). O princípio inovador do dicionário é que os significados individuais das palavras encontram-se agrupados por conceitos, ideias ou áreas semânticas. Cada um desses conceitos, que são 1.052 (chamados também de keywords), é dividido em seções menores, que aparecem em uma lista numerada de significados, permitindo ao usuário escolher aquele que mais 
corresponde à ideia que pretende expressar. Conforme explicado na introdução desse dicionário, ele está baseado em um corpus, isto é, o Longman Corpus Network, cujo corpus principal, o Longman Lancaster Corpus, contém mais de 30 milhões de palavras, reunindo as variantes britânica, norte-americana e outras, com vários graus de registro (de informal a formal) e alto nível de frequência das escolhas lexicais inseridas. Aos exemplos é dada muita importância, assim como à facilidade de acesso e à clareza das definições. Os padrões gramaticais e colocacionais são apresentados em negrito e, apesar do agrupamento por conceitos, o dicionário está em ordem alfabética. A seguir, um exemplo extraído do dicionário (s.v. Game/Match) para fins de apresentação das características até agora relatadas:

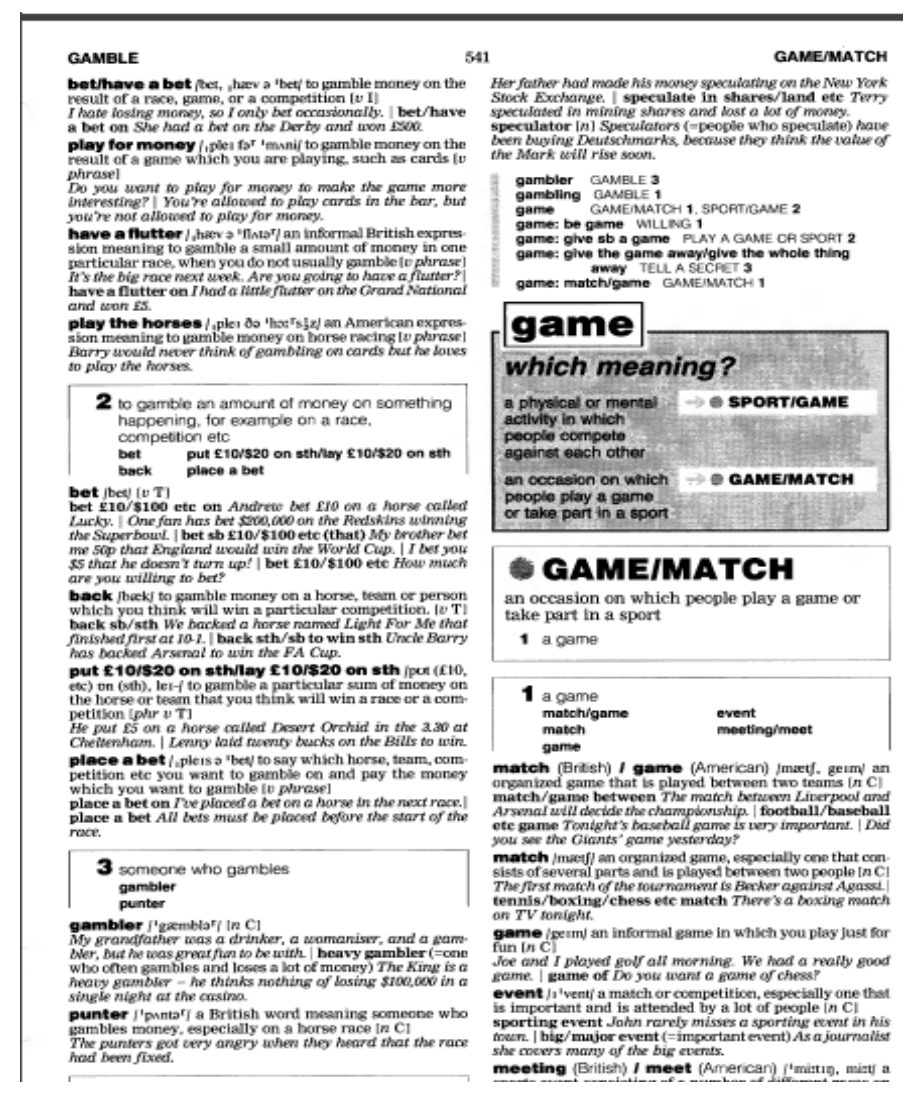

Figura 1 - Verbete Game/Match - LLA (1993[1997]) 
Assim como seu subtítulo lembra, The World's First Production Dictionary, o LLA está focado na produção em língua estrangeira, oferecendo informações explícitas para permitir, tanto para quem fala quanto para quem escreve, escolher a palavra mais adequada em relação a outras. Outra função especial do dicionário é fornecer canais de acesso à informação através de uma estratégia estabelecida em dois níveis: encontrar uma palavra-chave no dicionário por meio de sua posição alfabética tradicional (por exemplo, na Figura 1 acima, Gamble ou Game/Match) ou encontrar uma palavra, sintagma ou expressão idiomática listada em ordem alfabética dentro de cada seção, entre uma palavra-chave e outra (por exemplo, na Figura 2 abaixo, antes do verbete Study, encontramos uma lista alfabética de palavras - stubby, stuck, etc. - e, ao lado, a palavra-chave presente no dicionário na qual podem ser encontradas), graças a um sistema de referências cruzadas.

Do ponto de vista da produção, pensando tão-somente nas necessidades de preparação linguística mencionadas acima, constata-se que um dicionário onomasiológico como o LLA representa uma ferramenta muito importante para os intérpretes novatos que trabalham com a língua inglesa como língua B. A utilização de mapas conceituais e estudos sobre "ontoterminologia" não são novos dentro da área de formação e atuação dos intérpretes (apesar de a maioria dos estudos concentrar-se, de fato, na terminologia), como demonstra o trabalho de Bertaccini e Veronesi (2010), viabilizando que esses profissionais trabalhem com bancos de dados, glossários e outros recursos de forma mais interativa e dinâmica, além de possibilitar o uso de redes semânticas mais flexíveis capazes de ligar os conceitos.

No que diz respeito ao uso específico que os intérpretes novatos, usuários especiais de dicionários, podem fazer do LLA, vale a pena relembrar que, durante a sua preparação, além de estudar a terminologia específica da área em que irão interpretar e o background geral do palestrante, os intérpretes devem igualmente reforçar e atualizar as suas competências de língua geral, revisando assim padrões colocacionais, fraseologias e a pronúncia de algumas palavras, além de buscarem sinônimos, antônimos, etc., tudo para uma correta produção na língua 
inglesa. $\mathrm{O}$ intérprete poderia fazer isso a partir de palavras-chave extraídas do campo temático do congresso ou palestra, aproveitando para estudar, por meio da rede conceitual apresentada por um dicionário como o LLA, o léxico que caracteriza tal área, seus verbos, expressões idiomáticas, colocações, inter alia. Para entender na prática o tipo de informações e auxílio que o LLA poderia oferecer para um intérprete com inglês como língua $B$, suponha-se que ele deva traduzir uma palestra sobre o funcionamento e os sistemas de acesso das universidades no seu país, para um público de falantes anglófonos. Graças a um dicionário como o LLA, o intérprete pode, de maneira fácil e rápida, buscar uma palavra como Study na letra $S$ ou ir diretamente para uma das palavras-chave, Study, encontrando, assim, as seguintes informações:

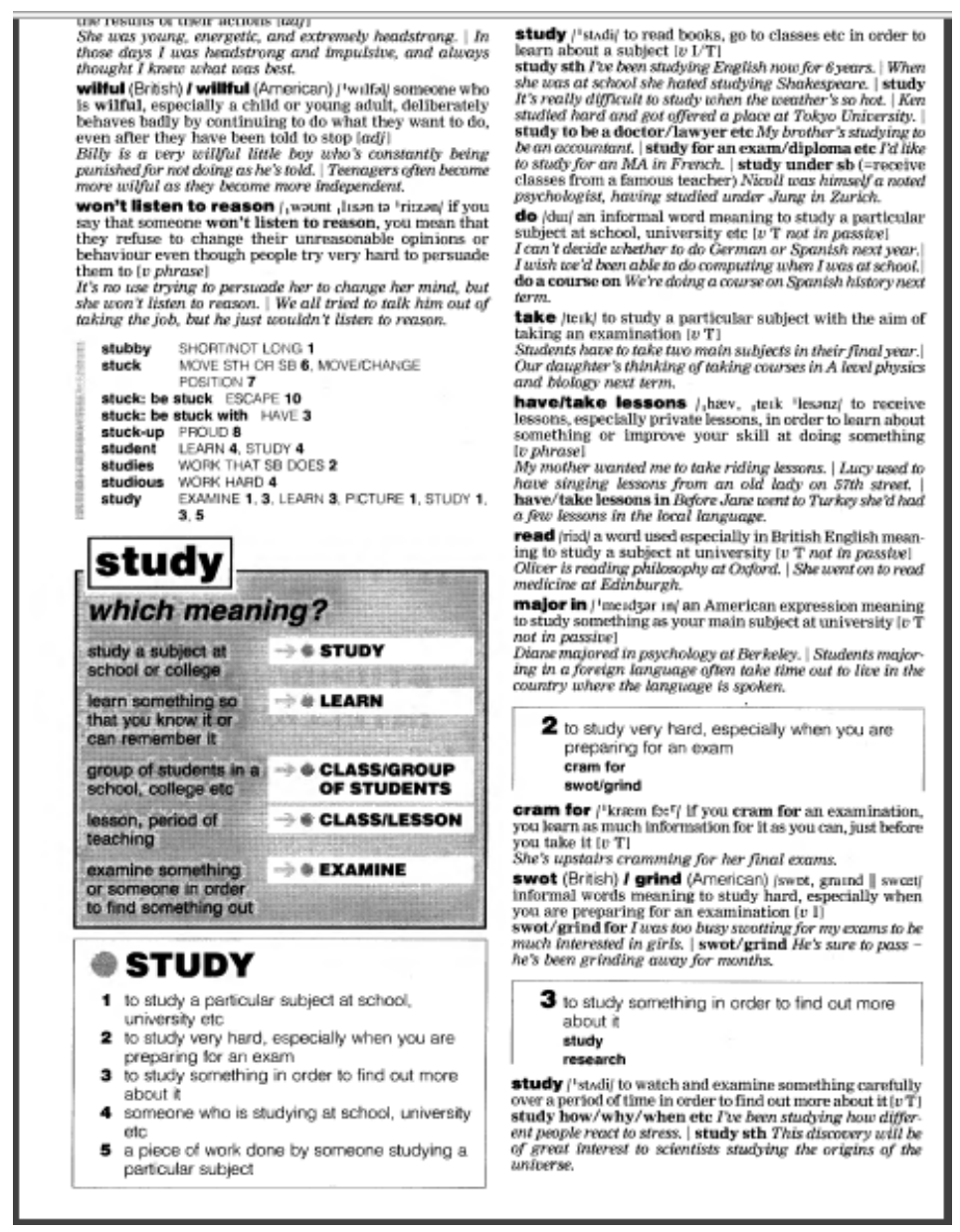

Figura 2 - Verbete Study - LLA (1993[1997] 
O usuário "encontra seções divididas por definição, que são valores básicos aplicáveis a um grupo de palavras, e escolhe qual dessas seções melhor define sua ideia" (Lunkes, 2014, p. 99). Os verbetes apresentam a indicação ortográfica, fonológica e morfológica, além da definição, exemplos, marcas de uso, fraseologia, entre outras possibilidades. Através da leitura dessas duas páginas do dicionário, em que se encontram condensadas informações e léxico de base conectados à área geral da educação, o intérprete consegue rapidamente adquirir e/ou revisar seus conhecimentos linguísticos de base, além de ser encaminhado para outros conceitos como learn, class, lesson, teach, examine etc., os quais, por sua vez, o levarão para outras seções, ampliando e reforçando assim seus conhecimentos relativos ao vocabulário geral de forma gradual, fácil e dinâmica.

Acreditamos que a utilidade do LLA não se refira exclusivamente à perspectiva da produção do intérprete, mas também à compreensão. Esse profissional, durante sua preparação, deve prever tanto o que será proferido pelo palestrante quanto como será dito. Mesmo que ele precise interpretar apenas do inglês para a sua língua materna, a circunstância de poder revisar e estudar os padrões e o comportamento da língua que será passiva durante o evento de interpretação constitui já uma maneira válida de se preparar, sempre na ótica da previsão e da antecipação, peculiaridades da profissão do intérprete.

\section{Considerações Finais}

O objetivo deste trabalho foi destacar a importância que dicionários onomasiológicos como o Longman Language Activator têm para a preparação dos intérpretes novatos, uma categoria especial de usuários de obras lexicográficas devido às peculiaridades da profissão e ao tempo de estudo e uso de suas línguas. O setting e as características intrínsecas da interpretação quase não permitem ao intérprete fazer pesquisa e estudar durante o evento. Por conseguinte, esse profissional é obrigado - para atingir uma elevada qualidade final da tarefa - a concentrar seus esforços e pesquisas antes do trabalho, tentando prever e antecipar o que e como será dito. Durante essa fase de preparação, muitas ferramentas são utilizadas 
pelos intérpretes, preferivelmente caracterizadas por uma consulta fácil e intuitiva, por evidentes questões de prazos muito limitados. Entre tais recursos, um dicionário onomasiológico como o LLA pode revelar-se fundamental para reforçar as competências relativas ao vocabulário geral do intérprete, pois ele deve preparar-se não apenas em relação ao léxico especializado da área em que trabalhará, mas também em relação ao léxico geral, a fraseologia, os padrões colocacionais, inter alia.

Após apresentar alguns estudos disponíveis sobre lexicografia e interpretação, o artigo abordou a importância da preparação para atingir um desempenho de qualidade durante um evento de interpretação, tendo como enfoque o intérprete novato e a necessidade de uma preparação que não somente estude a terminologia da área, mas também revise e solucione dúvidas sobre o léxico geral da sua língua B. No terceiro momento, foram tratadas as combinações linguísticas, destacando que é comum interpretar para a língua $B$, além da premente necessidade da consulta aos recursos lexicográficos para fins de produção linguística. Ao final, foram explanadas as principais características de dicionários onomasiológicos, analisada a micro e a macroestrutura do LLA, bem como sua relevância para a preparação linguística dos intérpretes novatos.

Para que um dicionário onomasiológico como o LLA seja mais adequado às necessidades de preparação dos intérpretes, dois aspectos fundamentais deveriam ser levados em consideração e, idealmente, integrados: o primeiro, fácil de ser concretamente implementado, se refere à possibilidade de poder consultar o dicionário online ou de poder adquirilo em formato eletrônico. Conforme afirma Sierra, "an on-line dictionary is more up-to-date and more easily updated than a printed book. On-line dictionaries allow users to look for information via a range of potential routes" (Sierra, 2000, p. 227). Infelizmente, este não é o caso do LLA (e, conforme é do nosso conhecimento, de nenhum outro dicionário onomasiológico de língua inglesa), pois ele ainda não possui uma versão eletrônica, ao contrário do Longman Essential Activator (da mesma editora, mas designado para falantes não nativos com proficiência préintermediária a intermediária, ou seja, não adequado às competências linguísticas elevadas dos intérpretes novatos), que já está disponível em 
formato eletrônico. Tanto devido ao deslocamento (os intérpretes trabalham em vários locais diferentes e é pouco prático carregar os dicionários impressos), mas em especial por questões de rapidez da consulta, os recursos e ferramentas mais adequadas para esse tipo de profissional devem ser de consulta rápida e de navegação intuitiva (Costa; Pastor; Muñoz, 2014). Também Valentini (2002) afirma que a rapidez de consulta e a relativa simplicidade e intuitividade de uso da ferramenta faz com que ela seja a mais indicada para as necessidades dos intérpretes, diferentemente dos programas para tradutores, que podem ser mais complexos, porque é o "fator tempo" que faz toda a diferença entre as duas profissões.

Em segundo lugar, um recurso lexicográfico como o LLA poderia atender de forma muito mais completa as necessidades dos intérpretes se integrasse a perspectiva terminológica que "se centra únicamente en los términos, o palabras propias de un campo de especialidad, entendida la especialidad como registro funcional de base temática" (Cabré, 1995). Semelhantemente à organização interna do já citado Longman Essential Activator, que apresenta bancos de palavras pertencentes a trinta áreas diferentes, o LLA também poderia dividir-se em áreas temáticas, como Educação, Esporte, Tecnologias, Medicina etc. e, dentro delas, incluir subseções que apresentassem, sempre em uma estrutura onomasiológica, as palavras especializadas daquela área juntamente ao léxico geral, fraseologia e tudo o que o LLA já oferece. Dessa forma, antes de uma palestra sobre o funcionamento e sistemas de acesso das universidades, conforme o exemplo acima citado, o intérprete poderia estudar diretamente a partir de um ideal Longman Language Activator - Education, encontrando assim o léxico geral e especializado relativo à área da educação, em conjunto com a indicação ortográfica, fonológica e morfológica, exemplos, marcas de uso, fraseologia, entre outras.

Consultar um dicionário onomasiológico na própria língua $\mathrm{B}$ de trabalho poderia, assim, permitir aos intérpretes novatos a imersão em áreas distintas do conhecimento de forma muito mais rápida e intuitiva, graças à sua estrutura especial, apresentada e analisada neste trabalho. Ele é muito útil para revisão de léxico geral, padrões colocacionais e 
fraseologia, entre os outros aspectos já enumerados, que estão relacionados à área específica do evento para o qual o intérprete for chamado a atuar. Realizar este tipo de preparação linguística, em conjunto com a preparação temática geral e terminológica, poderia representar um grande diferencial e oportunidade de aperfeiçoamento ainda mais rápido da própria língua $\mathrm{B}$ de trabalho.

\section{Referências}

AIIC - World English. Working languages. 29 abr. 2012. Disponível em $<$ https://aiic.net/page/4004/what-are-working-languages-to-a-conferenceinterpreter/lang/1>. Acesso em: 01 jul. 2017

APIC - Associação Profissional de Intérpretes de Conferências. Classificação linguística. 2017. Disponível em: <http://www.apic.org.br/classificacao-linguistica/> Acesso em: 01 jul. 2017. BABINI, Maurizio. Do conceito à palavra: os dicionários onomasiológicos. Ciência e Cultura, São Paulo, vol. 58, n. 2, p. 38-42, Abr/Jun. 2006. Disponível em: <http://cienciaecultura.bvs.br/pdf/cic/v58n2/a15v58n2.pdf $>$. Acesso em: 18 dez. 2014.

BAJO, M.Teresa; DÍAZ-GALAZ, Stephanie; PADILLA, Presentación. The role of advance preparation in simultaneous interpreting: A comparison of professional interpreters and interpreting students. Interpreting, v. 17, n.1, p.1-25, 2015.

BERTACCINI, Franco; VERONESI, Elisa. La terminologia come supporto all'interpretazione. In: Formação em terminologia: da investigação em comunicação multilíngue às competências para o exercício profissional Realiter, 2000, Faro. Anais... Faro: Universidade do Algarve, 2000. Disponível em: <http://www.realiter.net/le-giornate/giornata-formazionein-terminologia-dalla-ricerca-in-comunicazione-multilingue-alle-

competenze-per-lesercizio-della-professione?lang=pt $>$. Acesso em: 03 jul. 2014

BILGEN, Baris. Investigating Terminology Management for Conference Interpreters. 2009. Dissertação (Mestrado em Translation Studies). University of Ottawa, ON, Canada. 
BUGUEÑO MIRANDA, Félix. Da classificação de obras lexicográficas e seus problemas: proposta de uma taxonomia. Alfa, São Paulo, vol. 58, n. 1, p. 215-231, 2014. Disponível em: $<$ http://seer.fclar.unesp.br/alfa/article/viewFile/5378/4924>. Acesso em: 10 dez. 2014.

CABRÉ, Maria Teresa. La terminología hoy: concepciones, tendências y aplicaciones. Ciência da Informação, vol. 24, n. 3, 1995. Disponível em: $<$ http://revista.ibict.br/index.php/ciinf/article/view/487/1600>. Acesso em: 20 dez. 2014.

CAMARGO, Patrícia G. Competência em Interpretação - um breve estudo da interpretação em língua B. TradTerm, São Paulo, v. 23, p. 13-33, set. $2014 . \quad$ Disponível em: <www.revistas.usp.br/tradterm/article/view/85506/88295>. Acesso em: 10 jan. 2016.

CAVALLO, Patrizia. A carga cognitiva em interpretação simultânea e as diferenças entre intérpretes e bilíngues. TradTerm, São Paulo, v. 25, p. 6181, 2015.2 Disponível em: $<$ http://www.revistas.usp.br/tradterm/article/view/103054/101337>. Acesso em: 15 dez. 2015.

Necessidades terminológicas dos intérpretes vs. as dos tradutores: análise de três produtos terminográficos multilíngues. Cadernos do IL, Porto Alegre, n. 54, p. 47-65, out. 2017. Disponível em: $<$ http://www.seer.ufrgs.br/index.php/cadernosdoil/article/view/67707>. Acesso em: 31 out. 2017.

CORPAS PASTOR, Gloria; COSTA, Hernani; DURÁN MUÑOZ, Isabel. A comparative User Evaluation of Terminology Management Tools for Interpreters. In: Proceedings of the 4th International Workshop on Computational Terminology, 2014, Dublin. Anais... Dublin, 23 ago. 2014. p. 68-76. Disponível em: <http://www.aclweb.org/anthology/W14-4809>. Acesso em: 10 nov. 2014.

GILE, Daniel. La terminotique en intérpretation de conférence: un potentiel à exploiter. Meta: journal des traducteurs / Meta: Translators' Journal, vol. 32, n. 2, $1987 . \quad$ Disponível em: 
<http://www.erudit.org/revue/meta/1987/v32/n2/002904ar.pdf>. Acesso em: 04 jul. 2014.

. Le modèle d'efforts et l'équilibre d'interprétation en interprétation simultanée. Meta: journal des traducteurs / Meta: Translators' Journal, vol. 30, n.1, p. 44-48, 1985. Disponível em: <http://www.erudit.org/revue/meta/1985/v30/n1/002893ar.pdf>. Acesso em: 10 fev. 2014.

. Testing the effort models' tightrope hypothesis in simultaneous interpreting: a contribution. Hermes Journal of Linguistics, n. 23, p. 153172, 1999.

Basic Concepts and Models for Interpreter and Translator Training. Revised edition. Amsterdam: John Benjamins, 2009. HEIMBURGER, Franziska. Getting at language use in translation history through dictionaries produced for interpreters. In: MikaEL - Electronic proceedings of the KäTu symposium on translation and interpreting studies 4, 2010. Disponível em: <http://www.sktl.fi/@Bin/40692/Heimburger_MikaEL2010.pdf>. Acesso em: 10 dez. 2014.

KALINA, Sylvia. Quality in Interpreting and its prerequisites. In: GARZONE, G.; VIEZZI, M. (eds) Interpreting in the $21^{\text {st }}$ Century. Amsterdam/Philadeplhia: John Benjamins, p. 121-130, 2002.

KÖPKE, Barbara; NESPOULOUS, Jean-Luc. Working memory performance in expert and novice interpreters. Interpreting, v. 8, n. 1, p.1-23, 2006.

LUNKES, Diego. Longman Language Activator (2002) e Longman Essential Activator (2006) como ferramentas para a produção textual nas aulas de inglês como língua estrangeira. Revista Cippus - Unilasalle, Canoas/RS, v. 3, n. 2, nov./2014. Disponível em: $<$ http://www.revistas.unilasalle.edu.br/index.php/Cippus/article/view/1539 L1200>. Acesso em: 13 dez. 2014.

MEAD, Peter. Interpreting: the lexicographers' view. The Interpreters' Newsletter, Trieste, n.9, 1999. Disponível em: $<$ http://www.openstarts.units.it/dspace/bitstream/10077/2221/1/12Mead.pdf >. Acesso em: 17 dez. 2014. 
MOSER-MERCER, Barbara. Banking on terminology. Conference interpreters in the electronic age. Meta: journal des traducteurs / Meta: Translators' Journal, vol. 37, n. 3, set. 1992. Disponível em: < http://www.erudit.org/revue/meta/1992/v37/n3/003634ar.pdf> . Acesso em: 05 jul. 2014.

NEJM, Carla Cynira Lima. Interpretação simultânea: a linguística de Corpus na preparação do intérprete. 2011. 205f. Dissertação (Mestrado em Estudos Linguísticos e Literários em Inglês) - Departamento de Letras Modernas, USP, São Paulo, SP.

RODRÍGUEZ, Nadia; SCHNELL, Bettina. A Look at Terminology Adapted to the Requirements of Interpretation. Language Update, vol. 6, n. 1, p. 2127 , 2009.

Disponível

em:

$<$ http://www.btb.termiumplus.gc.ca/tpv2guides/guides/favart/index-

fra.html?lang=fra\&lettr=indx_titls\&page $=90 H A H v m F z k g E . h t m l>$. Acesso em: 05 jul. 2014.

SAN VICENTE, Félix (ed.). Lessicografia bilingue e traduzione: metodi, strumenti, approcci attuali. Monza: Edizioni Polimetrica, 2006.

SÁNCHEZ, María; PORCIEL, María; SERRAT, Iris. Exploring Current Research in Translation and Lexicography. InTRAlinea, 2014. Disponível em:

$<$ http://www.intralinea.org/specials/article/exploring_current_research_in_t ranslation_and_lexicography>. Acesso em: 15 dez. 2014.

SERVOZ-GAVIN, Delphine. Stratégies de préparation de conférence: du novice à 1'expert. 2014. 151f. Dissertação. (Mestrado em Interpretação). Faculdade de Letras, Universidade de Lisboa, 2014.

SIERRA, Gerardo. The onomasiological dictionary: a gap in lexicography. In: EURALEX PROCEEDINGS, 2000. p. 223-235. Disponível em: $<$ http://www.euralex.org/elx_proceedings/Euralex2000/027_Gerardo\%20SI ERRA_The\%20onomasiological\%20dictionary_a\%20gap\%20in\%20lexicogra phy.pdf>. Acesso em: 12 dez. 2014.

SIN-WAI, Chan (ed). 2004. Translation and Bilingual Dictionaries. Tübingen: Niemeyer, 2004.

VALENTINI, Cristina. Uso del computer in cabina di interpretazione. Inchiesta sui bisogni terminologici degli interpreti prima e durante la 
simultanea. 2002. Disponível em: <http://aiic.net/page/656/uso-delcomputer-in-cabina-de-interpretazione/lang/72>. Acesso em: 28 nov. 2014. VEISBERGS, Andrejs. Dictionaries and Interpreters. In: EURALEX PROCEEDINGS, 2006. p. 1219-1224. Disponível em: $<$ http://www.euralex.org/elx_proceedings/Euralex2006/146_2006_V2_Andr ejs\%20VEISBERGS_Dictionaries\%20and\%20Interpreters.pdf>. Acesso em: 30 nov. 2014.

WINTERINGHAM, Sarah Tripepi. The usefulness of ICTs in interpreting practice. The Interpreters' Newsletter, Trieste, n. 15, 2010. Disponível em: $<$ https://www.openstarts.units.it/dspace/bitstream/10077/4751/1/TripepiWi nteringhamIN15.pdf>. Acesso em: 16 dez. 2014.

\section{Referências lexicográficas}

LONGMAN ESSENTIAL ACTIVATOR. $2^{\underline{a}}$ ed. London: Pearson Education, 2006.

LONGMAN LANGUAGE ACTIVATOR. $7^{a}$ ed. Suffolk: Longman Group UK Limited, (1993) 1997.

\section{Resumo}

O presente artigo pretende estabelecer uma relação entre as áreas da Lexicografia e dos Estudos da Interpretação. Os intérpretes são usuários especiais de dicionários, cujas necessidades devem ser analisadas não somente sob a perspectiva terminológica, mas também lexicográfica. $\mathrm{O}$ foco deste estudo são os intérpretes novatos e a utilidade que um dicionário onomasiológico como o Longman Language Activator poderia ter durante a preparação para um trabalho de interpretação. Para tal fim, suas micro e macroestrutura são analisadas, mostrando as vantagens que uma obra dessa natureza poderia trazer para esses profissionais.

Palavras-chave: Lexicografia; Estudos da Interpretação; intérpretes novatos; dicionários onomasiológicos; Longman Language Activator. 


\begin{abstract}
This paper aims to bridge the field of Lexicography and that of Interpreting Studies. Interpreters are special users of dictionaries whose needs should not only be analyzed from a terminological point of view, but also from a lexicographical one. This study focuses on novice interpreters and the usefulness of an onomasiological dictionary such as the Longman Language Activator when preparing for interpreting gigs. For this purpose, the micro and macrostructure of the dictionary are analyzed and the advantages that this kind of dictionary can bring to these professionals are shown.

Keywords: Lexicography; Interpreting Studies; novice interpreters; onomasiological dictionaries; Longman Language Activator.
\end{abstract}

